See discussions, stats, and author profiles for this publication at:

https://www.researchgate.net/publication/45706218

\title{
On Coffee Talk and Break- Room Chatter: Perceptions of Women Who Gossip in the Workplace
}

Article in The Journal of Social Psychology · June 2010 DOI: $10.1080 / 00224540903365430 \cdot$ Source: PubMed

CITATIONS

9

3 authors, including:

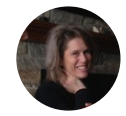

\section{Sally D Farley}

University of Baltimore

18 PUBLICATIONS 157

CITATIONS

SEE PROFILE
READS

354

Some of the authors of this publication are also working on these related projects:

Project

Are nonverbal engagement signals or self-reported attitudes

better predictors of behavior? View project

All content following this page was uploaded by Sally D Farley on 20 October 2015.

The user has requested enhancement of the downloaded file. 


\title{
On Coffee Talk and Break-Room Chatter: Perceptions of Women Who Gossip in the Workplace
}

\author{
SALLY D. FARLEY \\ DIANE R. TIMME \\ JASON W. HART

\section{QUERY SHEET}

This page lists questions we have about your paper. The numbers displayed at left can be found in the text of the paper for reference. In addition, please review your paper as a whole for correctness.

Q1: $\quad$ Au: 1987 in reference list. Please check all other mentions of this source.

Q2: $\quad$ Au: Please provide a brief bio for each author for the Author Notes section (approx. 2 to 4 sentences in length for each author)

\section{TABLE OF CONTENTS LISTING}

The table of contents for the journal will list your paper exactly as it appears below:

On Coffee Talk and Break-Room Chatter: Perceptions of Women Who Gossip in the Workplace

Sally D. Farley, Diane R. Timme, and Jason W. Hart 


\title{
On Coffee Talk and Break-Room Chatter: Perceptions of Women Who Gossip in the Workplace
}

\author{
SALLY D. FARLEY \\ University of Baltimore \\ DIANE R. TIMME \\ Albright College \\ JASON W. HART \\ Christopher Newport University
}

\begin{abstract}
The present study examined perceptions of female gossipers in the 10 workplace. Male and female participants $(N=129)$ were asked to think of a woman who either frequently or rarely contributed negative information about other people during conversation. Participants then completed ratings on the target using the six dimensions of the FIRO-B. As predicted, high gossipers were perceived as having a greater need to exert control of others, but less need for others to control them, than low gossipers. Higher 15 gossipers were also perceived as less emotionally warm than low gossipers. The implications of these findings for gossip research are presented.
\end{abstract}

Keywords: gossip, power, work

THE WORKPLACE PROVIDES A FERTILE GROUND for gossip to flourish. Formerly defined, gossip refers to situations in which people discuss intimate 20 details about other people while not in their presence (Foster, 2004; Rosnow, 2001). In the workplace, people may use gossip as a coping mechanism for dealing with stressful workplace situations (Crampton, Hodge, \& Mishra, 1998). Gossip between workers can also clear up matters that are not explained well in the formal communication system (Noon \& Delbridge, 1993). In fact, the success

The authors would like to thank their participants, students enrolled in Albright College's Degree Completion Program.

Address correspondence to Sally D. Farley, Division of Applied Behavioral Sciences, University of Baltimore, 1420 N. Charles St., Baltimore, MD 21201, USA; sfarley@ubalt.edu (e-mail). 
of organizational communication during times of change can be measured by the number of rumors that are spreading throughout the organization (Bordia, 30 DiFonzo, \& Schulz, 2000). Although gossip and rumor may overlap to some degree conceptually, these concepts differ in two important ways: (1) Individuals are less likely to question the veracity of gossip than rumor, and (2) gossip pertains exclusively to people, whereas rumors may spread about events (Foster \& Rosnow, 2006). Spreading gossip can also promote an individual's own self- 35 interest in ensuring that his/her "voice" is heard in a situation, thereby influencing others' perceptions since the gossiper may be seen as the "gatekeeper" of important information (Guerin \& Miyazaki, 2006; Noon \& Delbridge, 1993). The present paper focuses on how individuals perceive female gossipers in the workplace.

Researchers have been unable to reach a consensus on the significance and functions of gossip (Jaeger, Skleder, Rind, \& Rosnow, 1994; Leven \& Arluke, 1985). Although some researchers suggest that gossip includes positive information (Leven \& Arluke, 1985), others imply that gossip must be negative, or at least, that the information discussed is meant to be private (Foster, 2004). 45 Recent evidence has also demonstrated that it is negative gossip, not positive gossip, that is effective for increasing the intimacy of social bonds (Bosson, Johnson, Niederhoffer, \& Swann, 2006). In addition, there is disagreement over the relative importance of gossip. Some authors have described gossip as "trivial," "superfluous," and "not significant" (Ben-Ze'ev, 1994; DiFonzo, 50 Bordia \& Winterkorn, 2003; Jaeger, et al., 1994), the purpose of which is to entertain (DiFonzo, et al., 2003; Goodman, 1994; Levin \& Arluke, 1987; Nevo, Nevo, \& Derech-Zehavi, 1994). Gossip should not be dismissed merely as idle chatter, however (Levin \& Arluke, 1987). Research points out that gossip serves to enforce group norms, allows for indirect social comparisons, 55 increases intimacy of social bonds, communicates information, clarifies group membership, and enhances perceptions of status, power, or esteem (Ben-Ze'ev, 1994; Dunbar, 2004; Foster, 2004; Goodman, 1994; Jaeger, et al., 1994; Leven \& Arluke, 1985; Nevo, et al., 1994; Noon \& Delbridge, 1993, Rosnow, 2001). Dunbar (2004) offers perhaps the most extreme defense of gossip, arguing that 60 "gossiping is ... the core of human social relationships, indeed of society itself" (p. 100).

Recently, researchers have used evolutionary psychology to provide a theoretical framework for understanding the utility of gossip for developing and maintaining social networks (Dunbar, 1996, 2004; Mesoudi, Whiten, \& Dunbar, 65 2006). For instance, social gossip theory (Dunbar, 1993; 1996) states that human language evolved in response to the mounting pressures of maintaining beneficial interpersonal relations within expanding social networks. Furthermore, Dunbar (2004) argues that language serves four important social functions: (1) to monitor additions (e.g., births), defections (e.g., deaths), and movement (e.g., changes in 70 social status) of individuals within our interpersonal network; (2) to engage in 
impression management strategies for our personal benefit (e.g., to attract potential mates); (3) to penalize members of our social networks who do not abide by its rules, laws, or norms (i.e., free-riders); and (4) to receive direction or advice from others. Dunbar, Duncan, and Marriott (1997) found that gossip 75 accounts for almost two-thirds of conversation time, with much of that time dedicated to the former two social functions listed previously. Of particular relevance to the present study, Dunbar (2004) argues that social cognitive processes (e.g., theory of mind) are also vital for beneficial social interactions. Being able to take the perspectives of others helps us to determine whether a person is a 80 potential friend or foe. The use of gossip allows us to develop and maintain relations with friends, while also identifying and distancing ourselves and others in our social networks from free-riders. Based on these ideas, it would be interesting to examine how gossipers are perceived by others in their respective social networks.

Unfortunately, little empirical attention has been devoted to the perceptions of gossipers (Jaeger et al., 1994). Jaeger and colleagues (1994) describe two "disparate portraits" of gossipers. First is the view that gossipers are lonely social isolates who gossip to enhance their low self-esteem and status (see also Ben-Ze'ev, 1994; Levin \& Arluke, 1987). Second is the representa- 90 tion of gossips as self-assured connected people in the center of a social web, talking to and about many friends (Ben-Ze'ev, 1994; Jaeger et al., 1994). To test which portrait was more accurate, Jaeger and colleagues (1994) asked members of one college sorority to fill questionnaires about themselves and others in the group. Those who were perceived as gossiping a lot had lower 95 self-reports of need for social approval and higher levels of anxiety than those who were perceived as gossiping little. In addition, others rated high gossipers as less likeable but more socially connected in terms of numbers of friends. The clique that made up the high gossipers was quite an influential and powerful group in the sorority. Gossipers may be quite powerful because they argu- 100 ably are more central to a communication network, and they can use this position to "gatekeep" information, selectively revealing tidbits about others in status-enhancing ways (McAndrew \& Milenkovic, 2002; McAndrew, Bell, \& Garcia, 2007).

The present research examined the perceptions of gossipers in a workplace 105 setting. We focused on individuals' perceptions of the interpersonal wants and needs of female coworkers identified as either high or low gossipers (using the FIRO-B) (Schutz, 1958). We operationalized gossip as "communicating negative information about others" for three reasons: First, because social gossip theory prompts us to be more attentive to negative information as a mechanism for 110 guarding against free-riders (Dunbar, 2004; Enquist, \& Leimar, 1993). Second, research has shown that negative gossip, not positive gossip, is the more effective "social glue" for the creation of intimate social bonds (Bosson, et al., 2006). In addition, for this initial investigation, we wanted to tap into the general 
conceptualization of gossip, that it is primarily perpetrated by women and is 115 primarily negative.

We expected high gossipers to score higher on all subscales of the FIRO-B than low gossipers, with the exception of the wanted control subscale. Research suggests that low gossipers are less socially connected than high gossipers (Ben-Ze'ev, 1994; Jaeger et. al, 1994). Moreover, social gossip theory (Dunbar, 120 1993; 1996) appears to suggest that low gossipers' conversations are more likely to emphasize non-social content than the conversations of high gossipers. Therefore, it makes sense that high gossipers would score higher on a measure of interpersonal wants and needs than would low gossipers. The one exception to this argument would be for the wanted control subscale. For example, high gossipers are more likely to identify free-riders than are low gossipers, because they are privy to more information about the behavior of individuals within their social networks. High gossipers are likely to score lower on the wanted control subscale than are low gossipers, in part, because of their aversion to being exploited by free-riders.

\section{Method}

\section{Participants}

Approximately 500 non-traditional working students from Albright College were recruited via email to participate in the online survey. A total of 129 students responded, and 87 participants, whose ages ranged from 23 to $64(M=40)$ completed all 54 items (67\% of the total sample). Of the omitted surveys, $96 \%$ were omitted because the student complet'ed less than half of the survey. The high level of incompletes was probably due in part to the lack of incentives for completion. There were no incentives for participation (course credit, gift cards, etc.).

\section{Questionnaire}

The questionnaire consisted of demographic items (e.g., participant age, gender, etc.), and the subscales of the FIRO-B (Schutz, 1958). In the present study, items from the FIRO-B were modified to assess participants' perceptions regarding the target person rather than participants' own needs and behaviors. The FIRO-B consists of a total of 54 items, with 9 items for each of six subscales. Participants responded to each item using five-point Likert-Type scales (e.g., $1=$ never to $5=$ usually), giving each subscale a range of 9 to 45 when summated. In the present study, the scale demonstrated good internal consistency at the composite level $(\alpha=.94)$ and at the subscale levels (AE, $\alpha=.83, \mathrm{AW}, \alpha=.83, \mathrm{CE}, \alpha=.71, \mathrm{CW}, \alpha=.85, \mathrm{IE}, \alpha=.83$, IW, $\alpha=.85$ ). All of the reported Cronbach's alpha coefficients exceeded the commonly accepted threshold of adequate reliability of .70 (Nunnally, 1978). 


\section{Design and Procedure}

The design was a 2 (participant gender) x 2 (tendency to gossip: high vs. low) between-subjects factorial. Participants who volunteered to take part in the study were provided instructions on how to access the questionnaire on Survey Monkey ${ }^{\circledR}$. Once logged into the site, participants read an informational letter describing the study as a survey about "informal communication in the workplace." Participants were randomly assigned to condition and were asked to "think of a female coworker who frequently or rarely contributes negative information about other people during conversation" and evaluate the target using a modified version of the FIRO-B (Schutz, 1958). After completing the online materials on the targeted individual, participants were debriefed and thanked for their participation.

\section{Results}

We conducted a series of 2 (participant gender) x 2 (tendency to gossip: high vs. low) between-subjects ANOVAs on the summated scores from the six subscales of the FIRO-B. There was a significant main effect for tendency to gossip on the express control subscale, $F(1,70)=35.85, p<.001, \mathrm{~d}=1.57$, such that high gossipers were rated as needing more control $(M=42.63, S D=9.96)$ than were low gossipers $(M=24.62, S D=12.84)$. Tendency to gossip was also significant for the wanted control subscale, $F(1,77)=6.87, p=.01, \mathrm{~d}=-0.65$, such that raters perceived high gossipers as wanting others to control them less $(M=$ $22.94, S D=10.50)$ than low gossipers $(M=29.90, S D=10.81)$. For the express affection subscale, the main effect for tendency to gossip was marginally significant, $F(1,75)=3.75, p=.06, \mathrm{~d}=-0.47$, such that high gossipers were rated as less emotionally close $(M=29.35, S D=10.24)$ than low gossipers $(M=33.81$, $S D=8.86)$. No other statistically significant main effects or interactions were found.

\section{Discussion}

The present study provided mixed support for our hypotheses. As expected, high gossipers received higher ratings on the express control (need to exert power) dimension than low gossipers. Moreover, high gossipers were rated as less likely to want others to exert power over them (wanted control) than low gossipers. These findings are consistent with social gossip theory (Dunbar, 1993; 1996), especially with regard the policing function of gossip. High gossipers would be more likely than low gossipers to police free-riders (i.e., express control) and avoid being exploited by them (i.e., wanted control).

For women, gossip can become an agency of control, allowing them to reaffirm their own power within the organization. Because our study focused on

.


negative gossip, this is consistent with Kurland and Pelled's (2000) prediction that gossiping would increase coercive power. After all, women who gossip must grasp the opportunity to willingly, even aggressively, communicate to others knowledge about someone else. While it is true that need for control and perceived control are different constructs, it is intuitive that having a greater need for control would translate into behavior such that high gossipers would make more control attempts.

Contrary to our hypothesis, however, high gossipers were rated marginally lower on express affection than were low gossipers. Moreover, our predictions for wanted affection, express inclusion, and wanted inclusion were also not sup- 200 ported. Initially, these findings seem counterintuitive within the context of social gossip theory, because high gossipers are expected to more socially-connected within their social networks than are low gossipers, but one study found that high gossipers were perceived as having a lower need for social approval than low gossipers (Jaeger et al., 1994). Observers may fail to view gossipers as "needing" 205 inclusion or affection because they are already socially connected. These needs would not be perceived as deficient. In addition, both conditions involved communicating negative information about others in the workplace. Gossip involving negative information may be useful in policing free-riders, but it may not help individuals meet their other interpersonal needs (e.g., impression management). 210 Consequently, the perception that one desires power may also make him/her less likable in the eyes of others (Farley, 2008).

Stereotypical female social roles portray women as warm, nurturing, and relationship-oriented (Kawakami, White, \& Langer, 2000). Gossiping (specifically negative gossip), on the other hand, requires a strong personality and the 215 willingness to take several risks: the possibility of ruining relationships, hurting someone's feelings, or being seen as vindictive. Consequently, female gossipers sharing negative gossip with others may suffer from a loss of likability (Kawakami, et al., 2000).

One limitation of the present research involves the manipulation of an 220 instructional set. Specifically, our method allows for the possibility that correlates of tendency to gossip (like extraversion, or assertiveness, etc.) were responsible for differences in ratings. The alternative method that we considered, asking participants to rate a number of other individuals on scales of "gossip" and power, was discarded due to practical, ethical, and social desirability consid- 225 erations. Moreover, the present study focused only on perceptions about women who spread negative gossip in the workplace. Future research should examine whether the perceptions about female gossipers are also affected by the type of gossip they spread in the workplace.

Despite these limitations, the present study represents one of the few empiri- 230 cal studies designed to investigate perceptions of gossipers. Because of the dearth of research in this area, we decided to focus on the more traditional view of gossip—negative gossip. Clearly the results of this study would not generalize to 
perceptions of those who openly discuss positive gossip with others. Furthermore, the use of scenario studies would aid gossip researchers with problems of 235 control and clarify the ways in which real and hypothetical gossipers differ. It would also be beneficial in determining the extent to which gossiping is related to one's likeability.

Previous research has revealed that gossip is a rampant part of informal communication in organizations, especially during times of economic insecu- 240 rity and upheaval. Those times are currently among us. Since gossip is part of every workplace environment, understanding the dynamics of gossip is important if members of an organization are going to be effective and efficient communicators.

\section{AUTHOR NOTES}

\section{REFERENCES}

Ben-Ze'ev, A. (1994). The vindication of gossip. In R. F. Goodman \& A. Ben-Ze'ev (Eds.), Good gossip (pp.11-24). Lawrence, KS: University Press of Kansas.

Bordia, P., DiFonzo, N., \& Schulz, C. A. (2000). Source characteristics in denying rumors of organizational closure: Honesty is the best policy. Journal of Applied Social Psychology, 30, 2309-2321.

Bosson, J. K., Johnson, A. B., Niederhoffer, K., \& Swann, Jr., W. B. (2006). Interpersonal chemistry through negativity: Bonding by sharing negative attitudes about others. Personal Relationships, 13, 135-150.

Crampton, S. M., Hodge, J. W., \& Mishra, J. M. (1998). The informal communication net- 255 work: Factors influencing grapevine activity. Public Personnel Management, 27, 569-584.

DiFonzo, N., Bordia, P. \& Winterkorn, R. (2003, February). Distrust is a key ingredient in negative rumor transmission. Paper presented at the $4^{\text {th }}$ annual meeting of the Society for Personality and Social Psychology, Los Angeles, CA.

Dunbar, R. I. M. (1993). Coevolution of neocortical size, group size, and language. Behav- 260 ioral and Brain Sciences, 16, 681-735.

Dunbar, R. I. M. (1996). Grooming, gossip, and the evolution of language. London, UK: Faber and Faber.

Dunbar, R. I. M. (2004). Gossip in evolutionary perspective. Review of General Psychology, 8, 100-110.

Dunbar, R. I. M., Duncan, N. D. C., \& Marriott, A. (1997). Human conversational behavior. Human Nature, 8, 231-246.

Enquist, M, \& Leimar, O. (1993). The evolution of cooperation in mobile organisms. Animal Behavior, 45, 747-757.

Farley, S. D. (2008). Attaining status at the expense of likeability: Pilfering power through 270 conversational interruption. Journal of Nonverbal Behavior. 32, 241-260.

Foster, E. K. (2004). Research on gossip: Taxonomy, methods, and future directions. Review of General Psychology, 8, 78-99.

Foster, E. K. \& Rosnow, R. L. (2006). Gossip and network relationships. In D. C. Kirkpatrick, S. W. Duck, \& M. K. Foley (Eds.), Relating difficulty: The processes of construct- 275 ing and managing difficult interaction (pp. 161-180). Mahwah, NJ: Erlbaum.

Goodman, R. F. (1994). Introduction. In R. F. Goodman \& A. Ben-Ze'ev (Eds.), Good gossip (pp.1-8). Lawrence, KS: University Press of Kansas. 
Guerin, B. \& Miyazaki, Y. (2006). Analyzing rumors, gossip, and urban legends through their conversational properties. The Psychological Record, 56, 23-34.

Jaeger, M. E., Skleder, A. A., Rind, B., \& Rosnow, R. L. (1994). Gossip, gossipers, gossipees. In R. F. Goodman \& A. Ben-Ze'ev (Eds.), Good gossip (pp.154-168). Lawrence, KS: University Press of Kansas.

Kawakami, C., White, J. B., \& Langer, E. J. (2000). Mindful and masculine: Freeing women leaders from the constraints of gender roles. Journal of Social Issues, 56, 4-63. 285

Kurland, N. B., \& Pelled, L. H. (2000). Passing the word: Toward a model of gossip and power in the workplace. Academy of Management Review, 25, 428-438.

Levin, J., \& Arluke, A. (1987). Gossip: The inside scoop. New York, NY: Plenum Press.

McAndrew, F. T., Bell, E. K., \& Garcia, C. M. (2007). Who do we tell and whom do we tell on? Gossip as a strategy for status enhancement. Journal of Applied Social Psychology, 37, 1562-1577.

McAndrew, F. T., \& Milenkovic, M. A. (2002). Of tabloids and family secrets: The evolutionary psychology of gossip. Journal of Applied Social Psychology, 32, 1064-1082.

Mesoudi, A., Whiten, A., \& Dunbar, R. (2006). A bias for social information in human cultural transmission. British Journal of Psychology, 97, 405-423.

Nevo, O., Nevo, B., \& Derech-Zehavi, A. (1994). The tendency to gossip as a psychological disposition: Constructing a measure and validating it. In R. F. Goodman \& A. Ben-Ze'ev (Eds.), Good gossip (pp.180-192). Lawrence, KS: University Press of Kansas.

Noon, M. \& Delbridge, R. (1993). News from behind my hand: Gossip in organizations. Organization Studies, 14, 23-26.

Nunnally, J. C. (1978). Psychometric theory. New York, NY: McGraw-Hill.

Rosnow, R. L. (2001). Rumor and gossip in interpersonal interaction and beyond: A Social Exchange Perspective. In R. M. Kowalski (Ed.), Behaving badly: Aversive behaviors in interpersonal relationships (pp. 203-232).Washington, DC: American Psychological Association.

Schutz, W. C. (1958). FIRO: A three-dimensional theory of interpersonal behavior. New York, NY: Rinehart. 